\title{
What I actually said about medical ethics: a brief response to Toon
}

\author{
David Seedhouse University of Auckland, New Zealand
}

\begin{abstract}
It has been said that I am against medical philosophy.

This is a misrepresentation of my position. I am against conventional medical ethics teaching as it has to be done in medical schools, but very much in favour of

philosophy in medicine.
\end{abstract}

In an article in the journal (1) I am said to be against the enterprise of medical philosophy, and opposed to its inclusion in teaching programmes in medical schools. This is a serious misrepresentation of my position, and I would like to put the record straight.

Toon describes my position thus: I am part of a movement which is expressing disquiet about the achievements and future of 'medical philosophy or bioethics'. My specific contribution to this movement is: 'to argue that the sooner medical ethicists cease to exist the better'. More generally, since I am part of a movement which has 'common strands' I am also said (a) to think that academic standards in 'bioethics' are often poor (which I do), (b) to believe that philosophical analysis cannot solve the problems of ethical decision-making in medicine (I think quite the opposite, philosophical analysis is the only way to solve some of them), and (c) that doctors should not be trained in applied ethics but instead need to be made more 'morally virtuous' (a point I neither make nor comprehend).

Despite the brevity of the article to which he refers (it is only a little over two pages in length) Toon has got my argument almost entirely wrong. Thus it is worth stating what I really said in my article. I was attempting to make the following points. Firstly, that there can be no specialism of 'medical ethics' because:

' 1 ) It is not possible to distinguish ethical problems from non-ethical problems in the medical care of living beings. Consequently, medical ethics can have no special area of study.

2) While there is a long tradition of study of ethics by philosophers, in which various complex theories

\section{Key words}

Philosophy of medicine; teaching medical ethics. of morality have been developed, medical ethics is not this kind of enterprise. The discipline makes no attempt at the development of moral theory, but merely adapts its standard 'basic principles' in response to whatever medical situation it is currently considering. Medical ethics has no definitive core of knowledge or theory and is parasitic on moral philosophy and clinical practice' (2).

I supported these claims by arguing that it is both a theoretical and a practical error to imagine that there can be a separate discipline called 'medical ethics'. This is a theoretical error since:

'All interventions doctors choose to make in the lives of other human beings have ethical content, however apparently trivial or technical the encounter....

'There is not one set of interventions which have ethical content and another which does not: there are simply interventions made by people on people. This means there is no ultimate difference between the process undertaken by doctors deciding whether or not to refer a woman for an abortion, whether or not to offer a person a hip replacement, whether or not to keep a confidence, whether or not to prescribe an antibiotic, or whether or not to prescribe an antiinflammatory drug for a sore shoulder. In each case doctors must consider the clinical details and make a judgement about the likely medical outcomes, and in each case they must also weigh up non-clinical aspects' (2).

It is a practical error because the addition of a further 'medical specialism' (medical ethics) can only serve to mislead students into believing that ethical issues are somehow separate from the main body of clinical practice, or that ethical dilemmas occur only infrequently.

I further argued that:

'There are only two real choices for ethics experts who believe that doctors must receive a general education, and who wish to change medical training accordingly. They must either refuse to teach medical ethics at all, or if they decide to teach under this label must genuinely aim to make themselves 
redundant as ethicists as soon as possible (since they do not have a subject, and do not wish to sustain a deluding system)' (2).

Finally, I recommended that:

'The aim of enhancing general thinking about health care activity is to refuse to take a specialised focus and instead to encourage students to think critically, drawing on as much relevant theory and evidence as possible, in order to resolve difficulties of intervention.

'What is important is that medical students are enabled to become critical analysts and to know where and how to find ways ahead for themselves. If this broad approach is seen to have merit then the new generation of doctors will want to stitch in such methods to their own teaching, since they will recognise that every medical decision has a mixture of components, and that the best answers can be found only by a deliberative process which involves the range of factors.

'Instead of adding yet another specialism to the flagrantly overcrowded undergraduate curriculum, those with power to change medical education should be aiming to find room and respect for generalist teachers' (2).

What I most definitely did not say is that we should 'rely on a vague confidence that a new generation of moral generalists will emerge'. I am not hoping for doctors to become 'moral generalists', but all-round problem-solvers who are aware of the conceptual and practical limits of their craft.

What is more, having worked in three medical schools over a period of nine years, I am well aware that changes never 'emerge' but must always be fought for, and that any developments must be carefully planned, explained and justified. If the changes I propose are to happen then very precise job descriptions will be necessary. I very much doubm that advertisements for 'generalist teachers' wil: $\overrightarrow{\text { D. }}$ appear, but I would hope to see new medical schoos? posts in such subjects as 'health philosophy', 'healtt突 care history' and 'medical law'.

So how has Peter Toon managed to misunderstand so much? No doubt there are severaf possible explanations but I suggest that the problem may well have been caused by his own experience as a medical undergraduate (when there were very feves if any 'generalist teachers'). The main point of mb article was to argue that it would be a good idea if medical students were to be offered a more్ philosophical education, and not just introduced te the dramatic dilemmas (3) of 'medical ethics' Genuinely integrated into the curriculum, such ariv education would ensure that medical students would, at the very least, appreciate the differences between 'medical philosophy', 'bioethics', and 'medical ethics'. Despite the shortcomings of the present system I hope that other readers of myn editorial will have recognised that I was writing against medical ethics and for the philosophy of medicine within medical education.

David Seedhouse, BA, PhD, is Senior Lecturer cir Medical Ethics at the University of Auckland, Niv Zealand and Editor of Health Care Analysis: Jourmab of Health Philosophy and Policy.

\section{References}

(1) Toon P D. After bioethics and towards virtue? fourna of medical ethics 1993; 19: 17-18.

(2) Seedhouse D F. Against medical ethics: aे philosopher's view. Medical education 1991; 25䒠 280-282.

(3) Seedhouse D F. Ethics: the heart of health care Chichester: John Wiley and Sons, 1988.

\section{News and notes \\ Conference examines values in the news}

Journalists and scholars will come together on March 4-5 to wrestle with questions of values in the news at a national conference near Washington, DC.

The Reporting of Ethics and the Ethics of Reporting will feature sessions on journalistic objectivity and values, the moral dimensions of public policy, coverage of religion and media ethics.

Nationally known presenters from both the profession and the academy will include medical ethicist Arthur Caplan, church historian Martin Marty, journalism ethicists Theodore Glasser and Deni Elliott, FrontLine producer June Cross, former Washington Post Science Editor Victor Cohn and Washington Post Ombudsman Joann Byrd.

The conference will be held in conjunction with the annual meeting of the Association for Practical and Professional Ethics, which takes place March 2-4 in Crystal City, Va. For more information, contact Sandy Borden at 812/855-0261, or e-mail her at saborde@ucs.indiana.edu. 